\title{
PENERAPAN MODEL PEMBELAJARAN KOOPERATIF TIPE STAD TERHADAP PEMBELAJARAN MATEMATIKA SISWA KELAS X SMK PGRI 7 SURABAYA
}

\author{
Sebastianus Mere \\ (Pendidikan Matematika, Fakultas Keguruan dan Ilmu Pendidikan, Universitas PGRI Adi \\ Buana Surabaya) \\ mere@gmail.com
}

\begin{abstract}
Background of this research is caused by the lower of the education quality that is the used of unappropriate model by the teachers in teaching learning mathematics in classroom, so it makes the result of the teaching learning, kognitive ability, efective ability, and psikomotoric abilty are not ballance. Based on the explanation above, the teachers are suggested to create the education environment by using the appropriate model in teaching learning mathematics that is Cooperative STAD Model. This model is more presure the students to look for the solves in working in group with their friends. The statement of the problem in this research is "how is the student activities, responses, and the completeness of students' learning after the using of Cooperartive STAD Model at the second grade students of SMK PGRI 7 Surabaya". The purpose is to describe the students activities, responses, and the completeness of students' learning if the Cooperative STAD Model is attached at the second grade students of SMK PGRI 7 Surabaya. Data analysis techinique in this research is descriptive kualitative with the data source is the second grade students of SMK PGRI 7 Surabaya that number in 40 students and data collection technique is using observation, questionnaire, and post-test. Based on the research finding, it can conclude that the result of the students' learning at the second grade students of SMK PGRI 7 Surabaya with the relation as the topic in teaching learning are completeness with the $95 \%$ as clasical completeness percentage. The students' activities are more active with the percentage $87.65 \%$ that higher than the students are not active with percentage $12.35 \%$ and the students' responses at the teaching learning show the positive responses with the percentage $93.08 \%$.
\end{abstract}

Keywords: Cooperative STAD Model

\section{PENDAHULUAN}

Pendidikan merupakan penentu perkembangan kehidupan dimasyarakat. Masyarakat yang mempunyai tingkat pendidikan tinggi, maka pola berpikirnya mudah untuk diajak berpikir maju dan kritis, sebaliknya apabila tingkat pendidikannya rendah, maka pola berpikir untuk maju dan kritis itu sulit sekali. Suatu bangsa dikatakan maju, dapat ditinjau dari tingkat pendidikan yang dicapai oleh masyarakat. Kenyataan yang terjadi sekarang ini, pendidikan tidak hanya berorientasi pada masa lalu dan masa kini, tetapi juga seharusnya melihat jauh kedepan 
apa yang akan dihadapi peserta didik dengan adanya persaingan yang semakin besar dalam dunia pendidikan khususnya dibidang matematika.

Dengan perkembangan Ilmu Pengetahuan dan Teknologi (IPTEK), matematika memegang peranan yang sangat penting sebagai alat yang mendukung laju perkembangan dan persaingan yang terjadi sekarang ini. Matematika juga membantu manusia untuk berpikir logis, kritis, dan kreatif. Disamping itu juga merupakan sarana untuk menanamkan kebiasaan menalar dalam proses berpikir, karena itulah matematika termasuk salah satu pelajaran yang diberikan mulai dari tingkat dasar hingga lanjutan tingkat atas bahkan sampai ke perguruan tinggi.

Matematika merupakan ilmu universal yang mendasari perkembangan teknologi moderen. Matematika mempunyai peran penting dalam berbagai disiplin ilmu dan memajukan daya pikir manusia. Perkembangan pesat dibidang teknologi informasi dan komunikasi dewasa ini tidak terlepas dari hasil perkembangan matematika. Untuk menguasai dan mengembangkan teknologi dimasa depan, diperlukan penguasaan matematika yang kuat sejak dini (Permendiknas No.11 Tahun 2009: 337). Penguasaan matematika sejak dini sangat erat kaitannya dengan bagaimana cara guru memilih dan menerapkan metode pembelajaran di sekolah, khususnya di kelas. Tujuan pembelajaran matematika sekolah yang disebutkan di atas, pada dasarnya ditekankan agar peserta didik memiliki kemampuan "pemecahan masalah", "kemampuan penalaran", dan "kemampuan berkomunikasi”. Untuk itu, penguasaan konsep dalam pembelajaran matematika khususnya melalui latihan soal hendaknya dimulai dengan pengenalan masalah yang sesuai dengan situasi peserta didik".

Dalam realita yang terjadi dalam dunia pendidikan matematika, tidak semua siswa (peserta didik) memperoleh hasil yang sama dalam pembelajaran matematika. Ini bisa saja disebabkan karena motivasi atau kemauan setiap siswa untuk mempelajari matematika berbeda-beda. Untuk itu, perlu adanya terobosan dalam penyajian materi matematika dengan model/pembelajaran yang sesuai, agar anggapan bahwa belajar matematika butuh sesuatu yang ekstra atau sulit dipelajari bisa diminimalisir sebaik mungkin dan tidak terjadi lagi dalam pembelajaran matematika yang semakin modern dan menarik. Pencapaian hasil yang berbeda sangat jauh antara siswa yang satu dengan yang lain, disebabkan karena adanya kurang interaksi yang baik antara siswa yang satu dengan yang lain dalam setiap pembelajaran matematika di kelas. Hal ini sebaiknya cepat diantisipasi agar tidak terjadi kesenjangan dalam setiap 
pembelajaran matematika di kelas. Agar hasil atau kemampuan setiap siswa dalam menerima pembelajaran matematika selaras, maka perlu adanya kerja sama yang baik dalam setiap pembelajaran antara siswa yang satu dengan yang lain. Guru harus bisa menjadikan matematika sebagai pelajaran yang menarik untuk dipelajari. Model pembelajaran yang sesuai dalam hal kerja sama antara siswa yang satu dengan yang lain adalah model pembelajaran kooperatif (cooperative learning).

\section{METODE PENELITIAN}

Metode adalah cara yang harus ditempuh untuk mencapai suatu tujuan. Sedangkan penelitian adalah suatu usaha untuk menemukan, mengembangkan dan menguji kebenaran suatu pengetahuan. Jadi, metode penelitian adalah suatu cara atau teknik untuk memperoleh/dan mengolah data penelitian yang bersifat ilmiah. Menurut Rothwell \& Kazanas, metode adalah cara, pendekatan, atau proses untuk menyampaikan informasi. Sedangkan pengertian kata penelitian dalam Kerlinger (1986: 17-18), penelitian adalah investigasi yang sistematis, terkontrol, empiris dan kritis dari suatu proposisi hipotesis mengenai hubungan tertentu antarfenomena. Jadi, dapat disimpulkan metode penelitian merupakan cara ilmiah untuk mendapatkan data dengan tujuan dan kegunaan tertentu (Sugiyono, 2004:1).
Metode penelitian dalam penelititan ini adalah data dan sumber data, teknik pengumpulan data, teknik analisis data. Teknik pengumpulan data dalam penelitian ini adalah observasi, angket dan tes atau pre-test.

Analisis data dalam penelititan ini menggunakan rumus persentase aktivitas siswa

$$
=\frac{\text { frekuensi aktivitas siswa yang muncul }}{\text { frekuensi aktivitas siswa keseluruhan yang muncul }}
$$

(Kulsum, 2003: 45)

Ketuntasan hasil belajar dapat dihiutng menggunakan rumus : $E=\frac{n}{N} \times 100 \%$ (Sudjono, 2005:43)

Dengan :

$\mathrm{E}=$ persentase ketuntasan belajar

$\mathrm{N}=$ jumlah siswa yang belajar tuntas

$\mathrm{n}=$ jumlah seluruh siswa

Analisis data hasil pengamatan menggunakan rumus Persentase respon siswa $R=\frac{F r}{n} \times 100 \%$

Keterangan:

$\mathrm{R}=$ peresntase respon siswa

Fr $=$ frekuensi jawaban responden tiap aspek

$\mathrm{n}=$ jumlah respon 
Sebastianus Mere : Penerapan Model Pembelajaran Kooperatif Tipe STAD Terhadap Pembelajaran Matematika Siswa Kelas X SMK PGRI 7 Surabaya

\section{HASIL DAN PEMBAHASAN}

Dari hasil penelitian tentang hasil belajar dapat dilihat untuk nilai postes skor tertinggi yang diperoleh siswa adalah 90 dan skor paling rendah didapat oleh siswa adalah 55 dan untuk nilai rata-rata skor postes adalah 77,28 . Berdasarkan analisis di atas, hasil belajar siswa jika diukur dengan ketuntasan belajar siswa sesuai KKM, maka secara perorangan/individu siswa dinyatakan tuntas belajar jika telah mencapai $85 \%$ atau minimal mendapat nilai $\geq 75$. Sedangkan dari 40 siswa yang mengikuti postes, 38 orang siswa dinyatakan tuntas atau $95 \%$ dan 2 orang siswa dinyatakan tercapai. Berdasarkan hasil pengamatan tentang aktivitas siswa dari hasil penelitian, dapat dilihat bahwa rata-rata aktivitas siswa berdiskusi /atau bertanya antar siswa dengan guru sebesar $16,25 \%$, mengerjakan LKS sebesar 15,67\%, berdiskusi atau bertanya antar siswa sebesar 13,13\%, mendengarkan atau memperhatikan penjelasan guru secara keselrurhan sebesar 13,13\%, menanggapi pertanaan atau pendapat teman sebesar $12,50 \%$, menyajikan atau mempresentasekan hasil diskusi kelompok sebesar 11,25\%, menuis yang relevan terhadap KBM sebesar 3,54\% dan perilaku yang tidak relevan dengan KBM (misal; malamun, bermain, mengganggu teman, percakapan di luar pembelajaran berlangsung, dll) cukup rendah karena dipengaruhi siswa ingin selalu aktf dan berpartisipasi dalam model pembelajarann kooperatif tipe STAD yang diterapkan.

Sedangkan untuk angket respon siswa, menunjukkan respon siswa kelas X SMK PGRI 7 Surabaya terhadap penerapan model kooperatif tipe STAD yang menyatakan senang terhadap materi sebesar $100 \%$, yang menyatakan senang terhadap cara guru mengajar sebesar $80 \%$, yang menyatakan senang terhadap LKS sebesar $100 \%$, siswa yang menyatakan bahwa materi baru sebesar 97,5\%, yang menyatakan senang terhadap suasana kelas sebesar $90 \%$, siswa yang menyatakan baru terhadap cara guru mengajar $92,5 \%$, dan siswa yang menyatakan suasana kelas baru sebesar 90\%. Siswa yang menyatakan bahwa berminat untuk mengikuti kegiatan pembelajaran dengan model pembelajaran kooperatif tipe STAD sebanyak $100 \%$, LKS yang digunakan dapat membantu siswa belajar sebanyak $85 \%$. Sementara siswa yang menyatakan lebih banyak memiliki kesempatan berdiskusi dengan teman kelompok sebanyak 97,5\%, dan siswa yang menyatakan lebih banyak memiliki kesempatan menyajikan hasil diskusi sebanyak 90\%, siswa yang menyatakan memiliki kesempatan lebih banyak untuk berpikir dan mencoba mengerjakan secara individu sebanyak $85 \%$, siswa yang menyatakan lebih banyak memiliki 
kesempatan menanggapi hasil diskusi teman lain sebanyak $92,5 \%$.

\section{PENUTUP}

\section{Simpulan}

Ketuntasan hasil belajar siswa melalui penerapan model kooperatif Tipe STAD pada pokok bahasan relasi secara klasikal dinyatakan tercapai (tuntas) dengan persentase $95 \%$.

Aktivitas siswa melalui penerapan model kooperatif Tipe STAD pada pokok bahasaan relasi menunjukkan bahwa kegiatan siswa terlibat aktif dalam belajar karena persentase aktivitas siswa aktif yaitu $87,65 \%$ lebih besar dari aktivitas siswa tidak aktif yaitu $2,17 \%$.

Respon siswa terhadap kegiatan pembelajaran melalui penerapan model kooperatif Tipe STAD pada pokok bahasan relasi diberikan tanggapan positif yaitu $93,08 \%$.

\section{Saran}

Hendaknya guru lebih giat dalam memberikan motivasi kepada siswa sehingga siswa sangat antusias terhadap pelajaran matematika.

Penggunaan model pembelajaran kooperatif dalam proses pembelajaran masih merupakan hal yang baru, sehingga model pembelajaran kooperatif dapat disajikan salah satu alternatif dalam pemilihan model pembelajaran.
Model Kooperatif Tipe STAD dapat dikembangkan pada pokok bahasan yang lainnya sesuai dengan karekteristik model pembelajaran ini dan agar tercapai ketuntasan belajar maka seorang guru harus mampu memilih metode pembelajaran yang tepat dan sesuai dengan pelajaran yang akan disampaikan. Bukan hanya guru saja yang aktif dalam pembelajaran namun siswa juga harus ikut berperan aktif dalam pembelajaran.

Pembelajaran dengan menggunakan model Kooperatif Tipe STAD dapat digunakan sebagai masukan untuk meningkatkan mutu pendidikan yang sudah ada terutama di SMK PGRI 7 Surabaya.

Penggunaan model pembelajaran ini hendaknya dapat digunakan oleh peneliti lain untuk mendapatkan hasil ketuntasan belajar secara klasikal.

\section{DAFTAR PUSTAKA}

Basori dan Suwandi. 2008.memahami penelitian kualitatif. Jakarta: Rineka Cipta

Ibrahim, Muslimin. 2000. Pembelajaran Kooperatif.Surabaya: University Press.

Kalsum, Ummi. 2003. Model Pembelajaran Kooperatif Tipe Think-Pair-Share (TPS). Surabaya: Universitas PGRI Adi Buana Surabaya.

Margono,S. 2010. Metodologi penelitian pendidikan. Jakarta : Rineka Cipta.

Moleong, Lexy. 1993. Metodoloy Penelitian Kualitatif. Bandung: Rosdakarya.

Mulysa.2002.Kurikulum Tingkat Satuan Pendidikan. Bandung: Remaja Rosdakarya. 
Sebastianus Mere : Penerapan Model Pembelajaran Kooperatif Tipe STAD Terhadap Pembelajaran Matematika Siswa Kelas X SMK PGRI 7 Surabaya

Mulysa.2005.Menjadi Guru Profesional. Bandung:Remaja Rosdakarya.

Nurhadi,Yasin BY.2004. Pembelajaran Kontekstual dan penerapannya dalam KBK.Malang:Universitas Malang.

Rohani, Ahmad HM.2004. pengelolaan pengajaran.Jakarta:Rineka Cipta

Rusman. 2006. Pendekatan dan Model Pembelajaran. Bandung: Universitas Pendidikan Indonesia.

Rusman. 2010. Model-model pembelajaran. Jakarta: Rajawali Pres.

Sanjaya,Wina. 2009. Strategi Pembelajaran. Jakarta: Kencana.

Slameto.2010.Belajar dan Faktor-faktor yang mempengaruhinya.Jakarta Rineka Cipta.

Sudjana, Nana. 1989. Dasar-Dasar Proses Belajar Mengajar. Bandung:CV Sinar Baru.

Sudjana. 2005. Metode Statistik. Bandung: Tarsito.

Sugiyono. 2005. Memahami Penelitian Kualitatif. Bandung: Alfabeta

Sukiono. 2006. Matematika SMP Kelas VIII. Jakarta: Erlangga.

Sukmadinata, Nana Syaodih. 2004. Kurikulum dan Pembelajaran Kompetensi. Bandung: Kesuma Karya.
Tajul,Arifin. 2005. Penulisan Laporan Hasil Penelitian. Bandung: Puslit IAIN SGD.

Trianto. 2007. Model Pembelajaran Terpadu dalam Teori dan Praktek. Surabaya: Pustaka Ilmu.

Wijaya, Cece Tabrani. 1994. Kemampuan Dasar Guru dalam Proses Belajar Mengajar. Bandung: Remaja Rosdakarya.

http://id.Wikipedia.org/.11-20/.relasi dan fungsi. Diakses pada tanggal 20 desember 2015 pukul 20.45 .

http://ridwan202.wordpress.com/.kegiatan belajar dan prestasi.Diakses pada tanggal 20 desember 2015 pukul 13.15 .

http://ichaledutech.blogspot.com/2013/03/p engertian-belajar-pengertian.html Diakses pada tanggal 12 november 2014. Pukul 10.20.

http://sriyunai.blogspot.com/2012/12/strate gi-belajar-mengajarmatematika.html Diakses pada tanggal 12 november 2014 pukul 19.30 .

https://anrusmath.files.wordpress.com/2008 /07/model-pembelajaran kooperatif.pdf . Diakses pada tanggal 10 november 2014. 